University of Nebraska - Lincoln

DigitalCommons@University of Nebraska - Lincoln

Faculty Publications, Department of Psychology

Psychology, Department of

2006

\title{
Adapting Manualized Treatments: Treating Anxiety Disorders among Native Americans
}

\author{
Tami DeCoteau \\ Veterans Affairs Black Hills Health Care System \\ Jessiline Anderson \\ University of Nebraska at Omaha \\ Debra Anne Hope \\ University of Nebraska-Lincoln, dhope1@unl.edu
}

Follow this and additional works at: https://digitalcommons.unl.edu/psychfacpub

Part of the Psychiatry and Psychology Commons

DeCoteau, Tami; Anderson, Jessiline; and Hope, Debra Anne, "Adapting Manualized Treatments: Treating Anxiety Disorders among Native Americans" (2006). Faculty Publications, Department of Psychology. 569.

https://digitalcommons.unl.edu/psychfacpub/569

This Article is brought to you for free and open access by the Psychology, Department of at DigitalCommons@University of Nebraska - Lincoln. It has been accepted for inclusion in Faculty Publications, Department of Psychology by an authorized administrator of DigitalCommons@University of Nebraska - Lincoln. 
This is a U.S. government work and is not subject to U.S. copyright laws.

\title{
Adapting Manualized Treatments: Treating Anxiety Disorders Among Native Americans
}

\author{
Tami De Coteau, VA Black Hills Health Care System \\ Jessiline Anderson, University of Nebraska-Omaha \\ Debra Hope, Universily of Nebraska-Lincoln
}

\begin{abstract}
Alhough there is a small but grmaing body of litrature examining the psychopathology of anxiety among Native A mericans, no data are available mgarling the efficary of empiricaly; supported treatments for anxiety disordens amomg Native Americans. Morenver, exphtional challenges arise in aslapting mainstram appmaches to Native Americans, such as language barriers, contrasling beliejs alsut the calse and tratment of emotional ilhess between mainstream and traditional Native American culture, problems with hrumrank romplinnos, allowing extro time for rappont building, and the need for a spinitual component in the treatment of anxiety disorders. Notive dmoricans also comfront the challenges of moral living and low sorioeconomic slatus. The focus of this article is largely ronerptual in matum, informat by the limited psychopalhology data and the first author's experience with cognitive behavioral treatment protocols for anxioty disonders and the pwvision of mental health smvices to Native Americans. In this article we highlight the unique riball'nge's of adopting mamalized anxiety tratments for Native American chents.
\end{abstract}

$\mathrm{T}$ H:RF, Is IMTLE empirical evirlence regarding prevalence and phenomenology of anxiety disorders in Native Americans. However, existing data indicate that anxiety-related factors such as environmental distress, acculturation, depression, substance abuse, suicide, and health problems are widespread among Native Americas people (LaFromboise, 1988; McDonald, 1994; Nelson, McCoy; Stelter, \& Viuldenaigen, 1992; Walker, Lambert, Walker, \& Kivlahan, 1993). Given the high rate of stressors and health difficulties, it seens probable that Native Anericans experience an increased prevalence of anxiety disorders. In fact, some studies suggest elevated levels of self-report anxicty and anxiety sensitivity among Native American college students (McDonald, Jackson, \& McDonald, 1991; Zvolensky, McNeil, Porter, \& Stewart, 2001).

Methodological problems in using mainstream assessment measures with nommajority culture respondents has been well documented in the psychological testing literature (Dana, 1993; McDonald, Morton, \& Stewart, 1993; Trimble, 1977). Lack of culturally sensitive assessment tools and operational definitions of anxiety limit the generalizability of cognitive behavioral anxiety interventions. There is evidence, for instance, that culturally specific differences in communication style and worldview

1077-7229/06/304-309\$1 (00/0

(C) 2006 Association for Behavioral and Cognitive Therapies. Published by Elsevier Lid. All rights reserved.

Da Continulng Education Quiz located on pp. 341-342. may affect the clinical presentation of anxiety and lead to inaccurate interpretation of pathology in Native American people (De Coteau, Hope, \& Anderson, 2003).

There is good reason to suspect that cognitivebehavioral approaches can be effective with Native American populations because they address functioning in an individual's personal environment and promote situation-specific behavior changes (Renfrey, 1992). Nonetheless, the cultural sensitivity of cognitivc-bchavioral psychological interventions can be enhanced by assessing the client's worldview, using culture-specific assessment instruments, including culturc-specific rituals, and profiling contextual factors (Dana, 1996; McNeil, Porter, Zvolensky, Chaney, \& Kee, 2000).

This paper is largely conceptual in nature because of the lack of tindings regarding anxiety disorders among Native Americans. The manuscript is intended to provide gencral information to potential therapists about common issues and challenges that must be considered when adapting manualized anxiety interventions with Native American clients. The primary author, Tami De Coteau, is a federally recognized member of the Turtle Mountain Band of Chippewa Indians. The information presented is based on her personal experiences while working in a rural reservation community in the Midwest, and is neither comprehensive nor applicable to all tribal groups. The suggestions and opinions offered do not necessarily represent those of all Native American professionals or members of the community. 


\section{Challenges of Rural and Low Socioeconomic Environments}

Reservation communities present a number of interesting challenges for delivering psychological services becausc of their rural status and low socioeconomic environments.

1. Lack of transportation. It is uncommon for reservationbased clients to have transportation. Clinicians may need to transport their clients to and from the mental health clinic. When it is necessary to provide transportation for clicnts, therapists must keep in mind safety and ethics. One must ensure that the practice of transporting clients is authorized by the mental health agency in which the client is receiving services, have an appropriate third person in the vehicle, and be certain that there is insurance coverage for the client in the event of an accident.

2. Lack of telephones. Many clients do not have a home telephone. Client contact, including follow-up for missed visits, can be better achieved through mail and home visits.

3. Poor weather and road conditions. Reservation roads are often underdeveloped and inclement weather such as rain or snow can make them impassable. Unique situations arise when clients cannot be reached by road or telephone. It is important for clinicians to discuss these issues with their clients during their first visit. Agreements can be made to kecp a standing appointment time or consent forms can bc obtained to communicate through relatives.

4. Home visits. It may be necessary to conduct home visits with clients because of difficulty with transportation, telephones, and poor weather and road conditions. A new therapist to the community should be accompanied and introduced to the client by program personnel. Being accompanied by another staff member addresses issues of safety and ethics; but just as important, it addresses the issues of proper traditional protocol of introducing one's self, and the development of rapport and trust with the client. After introductions are made and the client has become more familiar with the therapist, one area of discussion may be whether home visits or office visits, or a combination of both, are preferred.

\section{Assessment and Diagnostic Challenges}

The Anxiety Disorders Interview Schedule-IV (ADISIV; DiNardo, Brown, \& Barlow, 1994) is one of the commonly used structured interview assessments for anxiety disorders. Although structured interviews such as the ADIS-IV provide reliable differential diagnosis and systematic assessment, they may not be culturally appropriate for Native American people (Kinowles, Gill, Beauvais, \& Medearis, 1992; Malgrady, 1996; Pewenardy; 2000).

Native American people traditionally transmil information through stories, dances, and songs (11ill, 1!997). Clinicians should know the diagnostic criteria well so they can allow the client to tell their story in a free-form fashion. Accordingly, semistructured interviews may need to be modified for use with Native Americam populations, with greater allowances for openecunded questions, and use of specific follow-up questions only when these questions have not been addressed by the client's open-ended account.

There are also important cross-cultural challenges that arise with regard to self-report measures of anxicly: Largely established on mainstream populations, these measures contain biases that reduce their validity with Native American clients. Even though an instrument is valid with a specific tribal population, it may be imalid with other groups because of importan regional, tribal, and dialectical differences. For instance, the psychometric characteristics of the Anxiety Sensitivity Index (ASI; Reiss, Peterson, Gursky, \& McNally, 1986) were investigated with a heterogeneous Native American college sample, and high levels of intemal consistency were found (Zvolensky et al., 200I). However, in a more recent study (Norton, De Coteat, Hespe, \& Anderiom, 2004) with a homogeneous sample of reservation-based Native Americans, poorly fit factor solutions were reported both in the original test construction molel (Zinbarg, Barlow, \& Brown, 1997) and throse in the Zvolensky et al. (2001) study. These studies cmphtitsize the importance of considering assessment measures within the framework of a specific subgroup rather than broader cultural groupings.

Culture-specific instruments such as the Native American Cultural Involvement and Detachment dnxiety Questionnaire (CIDAQ; McNeil et al., 2000) may provide a more reliable and valid means by which to measure culturally related anxiety. There is evidence to support the CIDAQ as a culturally sensitive measure of acculturation anxiety in both heterogeneous college and homogencous resenation-based samples (McNeil et al., 2000).

Culturally appropriate assessment should also include an evaluation of the client's cultural identity, level of acculturation, worldvew, beliefs about health and illness, identify ideals, and culture-specific symptoms (Dana, 1996; Lonner \& Ibrahim, 2002). Sometimcs, though a cognitive-behavioral manualized treatment protocol might label a cognition as a "dysfunctional" thought, it may actually reflect a client's cultural norms. Lacking understanding of cultural idioms of distress may lead to instances of labeling culturally normative thoughts as 
psyehological dystunction and underidentification of thought patterns that appear clinically insignificant but are actually culfurally deviant (Mciceil et al, 1997). Ansessment of the cultural context of the client's presenting problen through interviews with family members, clicitation of the client's own casual explanatory models, and a review of culture-specific psychopathology literature are esscoltial elements of cross-cultural assessment (AcNeil et al., 1997).

\section{Rapport-Building Challenges}

Melnonald a al. (1993) offer specific instructions for working with Nattive American clients. Their suggestions were emplosed throughout the primary athor's clinical work on the rescrvation and were found to be effective in facilitang rappont with Native American clients. McDona]cl el al. (1993) cauton clinicians against "establishing an expectancy for" these guiclelines, Instend, they suggest clinicians utilize the information to develop a "silent hypothesis" cluring assessment. The following is a summary of the ir suggestions as well as additional conments about the use of rituals.

1. Begin and and each session by shahing hemds. For many tribes, the hatndshake is a culturally appropriate way of communicalting respect. However, a firm handshake may construe aggression for some tribes. Simply return an equal amount of pressure and shaking that the client gives.

2. Eye contart. The belief that all Native American people aroid eye contact is somewhat of a stereotype. In fact, some tribes avoid eye contact, particularly with elders, to show respect, while others value direct eye contact. It is acceptable to ask the client about their eye contact after adequate rapport has been established.

3. Silente. Clinicians need to become comfortable with silence, possibly for long periods of time. Elders in particular tend to use silence to communicate their readiness to share information, pray, or show respect.

4. Langhter. Native American people love to laugh and often use teasing as a way of communicating. Laughter about difficult situations is common and serves as a coping mechanism. Become comfortable with laughter and do not discourage it.

5. Rituals and ceremonies. Acceptance and flexibility of unique beliefs about healing practices are necessary when working with Native American clients. For example, clients may choose to pray, sing, or burn sage, sweetgrass, or cedar. They may also wish to meet at a location in which they feel more spiritually comfortable. The sweat lodge, an age-old purification ritual of thanksgiving and forgiveness, is used to treat combat veterans with posttraumatic stress disorder. In the heat of the lodge, the participant "suffers" for all veterans and transition from the role and identify of a warrior to that of a societal member wilh new status and set of responsibilities. The sweat lodge can be a source of healing from traumatic cxpericnces and memories (Veterans Administration Substance Abuse and Post-Traumatic Stress Disorder Treatment Program, 1993). Christianity and traditional Native American spiritual beliefs intersect or parallel in the Native Amcrican Church, with peyote being the sacrament as is wine in Christianity. It should be understood that the Native American Church is also a source of healing from physical or cmotional problems (Hoxie, 1996).

Historically, Native Amcricans have conducted "giveaways" when being honored. One may give to a complete stranger because it is the honorable thing to do, or may give to honor a relative. In honoring a relative, that person also becomes honored in the eyes of the community, In essence, Native American clients practice gift giving as a way to express appreciation for the help they reccive, and to honor somconc. While the practices mentioned above are proper etiquete in Native American healing situations, mainstream psychological ethics consider them questionable. Therefore, clinicians should remain aware of safety issues and use good judgment about participating in such practices while remaining open-minded.

6. Time. Native American people tend to arrive later and leave later then the actual scheduled time. This has nothing to do with their ability to tell time, but rather their beliefs about time as circular, not linear. Native Americans tend to start when cveryone arrives and end when everyone finishes. Clinicians may need to be creative in accommodating for Native American clients who may be uncomfortable with weekly 50-minutc sessions.

\section{Humility}

Matheson (1996) suggests the entire field of psychology implies a superiority of the therapist over the client. Cognitivc-behavioral therapy in general requires the clinician to maintain a presence of competence in order to gain the client's respect. Such competency could be misconstrued as overconfidence to many Native Americans who value humility. Clinicians should be aware that most tribes believe humility is one of the most valued personality characteristics. Be sure to work with Native American clients as an equal.

\section{Language and Presentation}

When utilizing the manualized treatments for reservation-based Native Americans, one of the most commonly 
encountered chailenges is the amount of reading, writing, and receiving verbal instruction.

1. Low reading ability: Many clients may have low reading and writing ability because of inadequate education. Much of the treatment material may nced to be modified to facilitate understanding. It may be necessary to thoroughly cover all the information during session so clients are not expected to do any reading on their own.

2. Language barriers. Elderly and more traditional clients may spcak primarily their Native language and have a minimal understanding of English, so language facility is an important factor that may affect assessment and treatment. Language barriers delay the therapeutic process; though there are few bilingual clinicians, a translator can also be utilized. However, sometimes one must rely on family members or significant other to translate. The lack of translators presents some difficulty regarding confidentiality, and if the transiator is a family member or significant other, the presenting problems may be exaggerated or minimized. Translation difficulties present further challenges (Manson, Shore, \& Bloom, 1985), since Native and English languages lack some equivalent terms. And many Native American languages do not have words for certain emotions, the meaning rather being conveyed by a lengthy description of that emotion; this leads to problems of semantic equivalence and to difficulty in labeling thoughts (Dillard \& Manson, 2000). Materials may need to be modified to accommodate Janguage differences. It may be appropriate to have a translator, such as a relative, attend visits with the client.

3. Visual leamers. Native American people tend to be visual learners (Pewewardy, 2000). Clinicians need to be innovative, particularly with the educational components, in presenting the material. For instance, when describing the components of anxiety and their interaction, the clinician might ask the client to construct a drawing based on their understanding. The clinician can proceed to use the client's drawing, rather than those provided in the manual, for the remainder of the sessions. It is also important for clinicians to become comfortable with demonstrating material, rather than verbally explaining it.

4. Circular approach. The sequential and systematic style of manualized cognitive behavioral interventions may cause discomfort for Native American clients. Clinicians may need to slow the pace of therapy and allow for diversions in order to meet the situational and contextual needs of their clients. Extracting the most relevant picces of the conventional anxiety treatment and blending them with trulitional healing approaches also may case clients" amxicty and cultivate trust and rapport.

\section{The Extended Family: A Key Treatment Component}

In working with Native American clients, the presess of appropriate assessment and treatment should also focus on inclusion of family members (Sue \& Sue, [I!KI; Trimble \& Fleming, 1989). In order (o provide quality mental health care, the therapist must appreciate (i) the complex, intricate design of the extended family: (b) the cultural differences, even between trites, in the kinship/clanship systems, and (c) the fumily-related role expectations, such as the imolicment of the extended farnily in making major and even minor life decision. Including family members in the therapy process should be carefully discussed with the client. For eximple, does the client want certain fantly members of be present during sessions? If so, which sessions? Ithat issues does the client want 10 discuss with family members? Appropriate consent forms need on be obtained from all extended family who will be insolved in the thersys process.

\section{Homework Compliance}

A number of considerations arise that may make it difficult or even impossible for clients to complete homework assignments. length of sessions can be extended to allow for time to complete assignments in session. Clinicians should be sensitive to such obstacles, and they should not expect that the client will comsey to them these difficulties.

1. Living situation. Many Native American people live with extended family members. Particularly if they are living on the reseration, their place of resislence may be quite small, making a comfortable, quiet place to complete assignments unarailable.

2. Other responsibilities. Native Americans clicnts have a variety of important roles in their family. For example, a teenage girl, aunt, or grandmother may be expected to care for the children and inaintain household duties, as well as attend school or work. The importance of these oller responsibilities may' supersede homework or simply may not leave time to complete assignments.

3. Communication. As mentioned earlier, reading and writing conflicts with the traditional ways of communication, which occur most of ten throngh story, song. dance, or prayer. Rather than completing homework assignments on paper, clients and therapists can use their imaginations in developing songs, stories, or dances that help explain the client's experience of 
anxien. As mentioned earlier, spirituality is an integral part of Native Anerican life. One of the authors has used prayer and the ceclat ceremony as a healing pratice in therapy, particularly for cathartic release and expression of maladaptive emotions. Helping a Native American client in understanding their spiritual nature and identity may be the initial phase of wotking woward therapentic development of songs, steries, or dances to help explain the experience of anxiety. Mout Native Auterican people who have a clear self-and cultural-identity may not require mental heillh services.

\section{Exposure Challenges}

Whale many exposture situations may' not be arailable within the resenation community (e.g., crowded malls, muve the aters, cletators), a client's fear may still interfere with his or her functioning when traveling outside of the reservation and exposed to the feared stimuli. In these cases, therapists maty need to travel outside the community with the client, tuilize in-riso exposure or role-plays, and employ the ir imaginations to create useful exposure situations.

1. lark of rommunity resoures. lexposures can be difficult to complete in rural resesvation communities because of limited anailability of resources. For example, there miay not be clevators or high buildings available for clients sereking treatment for these fears. Nevertheless, these fears may interfere with the client's ability to seek medical services or emplorment off the reserration.

2. "Lumbody knows your name." Reservation populations lend to be very small, making it easy to know ereryone in the commmnity. Because of the extended family systems, it is often the case that the client is related to many people in their tribe. Thus, it may be impossible to accompany clients on an exposure outing without breaching confidentiality. Clients secking treatment for social anxiety disorder may also have difficulty finding environments in which they are uncomfortable (e.g., strangers). For example, though a cliest may experience social anxiety upon traveling outside of the commututy, the client may have difficulty identifying anxiety-prowoking social settings for exposure treatment within the community because of familiarity with most community members.

\section{Native American Worldyiew}

1. Individual. Most manualized treatments for anxiety focus on the individual and scldom include family members. Although this is a useful approach for majority culture clients, it may be less effective for Native American clients.
2. Collective Native Americans tend to possess a collective worldview that includes their extended family and tribe. This focus often means that family and tribal issues take precedence and they may judge themselves according to whether they are beneliting their tribe (Garrett \& Garrett, 1994). Their self-perception is based on how others within their tribal system view them. For instancc, a socially anxious Native American client may negatively cviluate themselves because their community members view them as failing to contribute to the tribe's continued harmony. Many treatment approaches try to intervene with this sort of interdependent view of self and cncourage the clicnt to view themselves as an individual part of the tribe, rather than as a part of the greater whole. A more effective treatment approach may be to help the client form a healthy interdependent view of themselves and behave accordingly, as in emphasizing the effect of treatment on the client's family and tribe: What is the outcome for the tribe, family, and client? Clinicians may also choose to invite extended family to attend sessions to accommodate the client's needs.

\section{Spirituality}

Many manualized anxiety interventions lack a spiritual component. This creates a problem when working with more traditional Native Americans who are very spiritual and consider their spiritual well being to be predictive of physical and mental health. Native American people typically strive for harmony between mind, body, and spirit. Therefore, when describing the three components (i.e., physiological, cognitive, behavioral) of anxiety, clinicians can include spirituality as a fourth component. Again, the client's drawings and/or stories can be utilized to facilitate communication and understanding between the clinician and client. Additionally, it may be advisable to consult with a traditional Native American healer and the client may wish to supplement treatment with spiritual practices.

\section{Summary}

There are a number of challenges and considerations for adapting manualized anxicty treatment for Native American clients. The information presented here is intended to provide general guidelines for modifying treatments, and may be particularly applicable to Native Americans living on reservations or in rural tribal communities in the Midwest. Although we feel that the information will help to prepare mental health professionals to more effectively treat Native American people with anxicty disorders, these are preliminary suggestions and should be employed with careful consideration. Moreover, it is hoped that this information will be a 
spark that ignites intcrest and future research to better understand anxiety disorders and develop more culturally appropriate treatments for Native American people. Clinicians who find themselves providing clinical services to Native Americans should seck appropriate crosscultural training and supervision while maintaining flcxibility in their approach. Aspiring clinicians will benefit from the increasing cmphasis on diversity and multicultural training within their graduate programs. The authors cncourage students to supplement their graduate course work with practicum experiences that provide exposure to Native American populations. Clinicians who serve Native American people need to seek ongoing advice from tribal elders and Native American providers in the communities in which they are working.

\section{References}

Danat, R. H. (1993). A comparison of three worry questionnaires. Behatiour Research and Therafy, 31, 51-56.

Dana, R. H. (1996). Culturally competent assessment practice in the United States. Joumal of Pemonality Assessment, 66, 472-487.

De Coteau, T. J., Ilope, D. A., \& Anderson, J. (2003). Anxiety, stress, and health, in Northern Plains Native Amcricans. Behavior Therapy, 34, 365-3\$0.

Dillard, D. A., \& Manson, S. M. (2000). Assessing and treating Anerican Indians and Alaska Natives. in I. Cuellar, \& F. A. Paniaģua (Eds.), flandbook of mental health (pp. 226-245). San Diego: Acirlemic Press.

DiNando, D. A., Brown, T. A., \& Barlow, D. H. (1994). Anxiety Disonters Interview Schedule for DSM-IV: I.ifelime Version (ADIS-IVLL). Albany, NY: Graywind Publications.

Garrett, J. 1., \& Garrett, M. W. (1994). The path of good medicine: Understanding and counscling Native American Indians. foumal of Mulicultural Connseling and Development, 22, 134-144.

Hill, R. T. G. (1997). Methodological approaches to Native American narrative and the role of porformance [Special isste: To hear the eagles cry: Contemporary themes in Native American spirituality, Part III - Historical reflectionss]. American Indian Quarterly, 21, $111-147$.

Hoxic, F. F. (Ed.). (1996). Encyclopedia of North American Indians Boston: Houghton Mifflin.

Knowles, T., Gill, J., Beauvais, A., \& Medearis, C. (1992). Teacher edication and the Roseburl Tribal Fducation Code. Tribal College, 4, 21-23.

LaFromboise, T. D. (1988). Amcrican Indian mental health policy. American Psychalogist, 43, 388-397.

Lonner, W. J., \& Ibrahim, F. A. (2002). Appraisal and assessment in cross-cultural counseling. In P. B. Pederson, J. G. Draguns, W. J. Lonner, \& J. E. Trimble (Eds), Counseling across cultures (5th ed., pp 355-379). Thousand Oaks, CA: Sage.

Malgady, R. G. (1996). The question of cultural bias in assessment and diagnosis ofethnic minority clients: Let's reject the null hypothesis. Professional Psychalogy: Research and Pratice, 27, 73-77.

Manson, S. M., Shore, J. II., \& Bloom, J. D. (1985). The depressive experience in American Indian communities: A challenge for psychiatric theory and diagnosis. In A. Kleinman, \& B. Good (Eds.), Culture and depression (pp. 331-368). Berkeley: University of California l'ress.

Matheson, L. (1996). Valuing spirituality among Native American populations. Counseling and Values, 41,51-58.

McDonald, D. (1994). New frontiers in clinical training: The UND Indians Into Psychology Doctoral Education (INPSYDF) Program. American Indian and Alaska Native Aental Healh Research, 5, $52-56$.

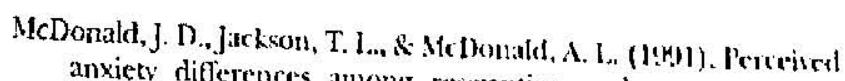
anxiety differences among rescosation and tom-tesenation Natise Anerican and majority culture cullege sudents fommal
of Indigenous Sindies, $271-79$ of Indigenous Sindies, 2, 71-79.

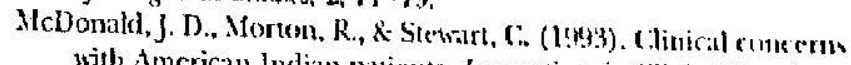

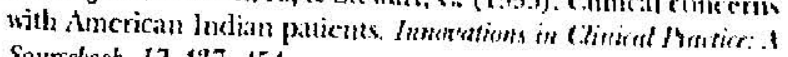
Soumelook, $12,437 \cdots+54$.

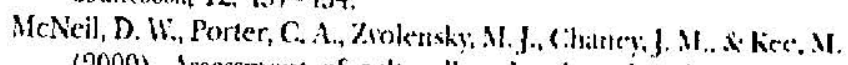

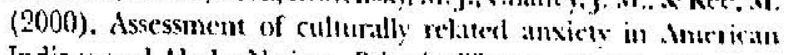

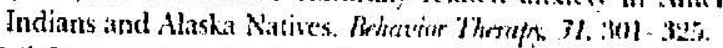

Mcxeil, D. W., Zuolensky, M. J., Porker, C. A. Rablitis, A., Mk l'heroun. T., \& Kee, M. (1997). Auxiety disorders in Anerican ludiam and Alaska Satives: Slessification and intencmiom. fustirn Iforth Senvice Primany Cam Porider, 22, 181-185.

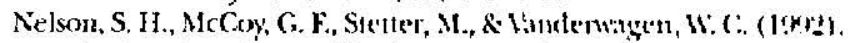

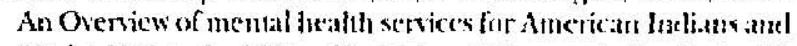

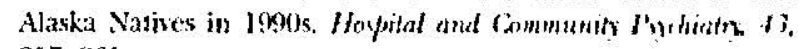
$257-261$.

Norton, P. J., De Colean, T. J., Jtupe, 1). A., \& Amierwit. J. (24)H). The factor structure of the inxiety Selpitivin Index atmong northern plains Native Americans. Brhazinit Rorarh and Therapi, 42, 241-24t.

Pewewardy; C. (2000). Learning styles of American Indian/Alaski Native students: $A$ review of the liserature and inmplicatimus tor

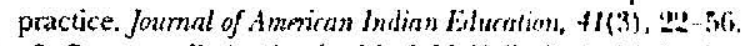

Reiss, S., Peterson, R. A., (iursk;, M., \& ItcNally, R. J. (1!1,kit). Anxie t? sensitivity, anxiely frequency: and the prodiction of fatsuluew. Behaviour Researth and Therafo, 2f, 1-8.

Renfrey, G. S. (1992). (ongnitive-lodation therapy and the Native American client. Beharior Therafn, 23,32l-340.

Sue, D. W., \& Sue, D. (1990). Counseling the rollumbly diffortat: Thon and practice (2nd ed. pp 175-188). New link: folum Wiley \& Scrus.

Trimble, J. E. (1977). The sujourner in the American Intian comrnunity: Methodological issues and colicetus finmal of Social lssues, 33, 159 17:5.

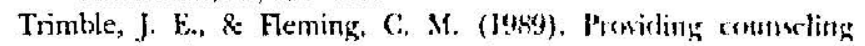
services for Native American Indians: Clikm, combclor, and community characteristics. In P. B. Pedermell. I. (i. Mratials. W. J. Lonner, \& J. E. Trimble (F.d5,), Cenunling nons rultum (3rd ed., pp 177-204). Ifonolulu: L'niversily of Hatsaii l'rew.

Veterars Administration Substance Abuse and P'osuraumulic Surs

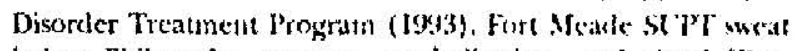

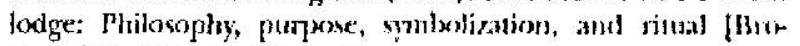
chure] Fort Meade, SI): Author.

Walker, R. D., Lambert, W. D., Walker, I.S., \& Kivhls:m, D. R. \{l(M13). Treatment implications of comortid psychoputholegy in suncr. ican Indians astd Alaskat Natives, Cinlum, Medicine, nul Psychiniry. $16,555-572$.

Zinbarg, R. E., Barlow, D. 11. \& Brown, T. A. (19m). Hicrarrhiral structure and general factor saturation of the Anxiety Seusitivity Index: Evidence and implications. Physhoghorl Asmumm, 9. $277-284$.

Zvolensky, M. J., McNeil, D. W., Porter, C. A., \& Sterar1, S. (2001). Assessment of anxiety sensitivity in young Anerican Indians and

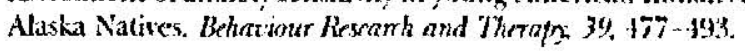

Tami De Coteaul is now at the Departunent of Veterans affairs in the Black Hills of South Dakola. Most of the work for this parper was conducted as part of her APA. Ninority fedlowship devring hes doctoral graduate training while at the University of NotwraskLincoln.

Addiess correspondence to Debra A. Hope, Depasumem of Psycholog; University of Nebraska-Lincoln. I incoln, NF cs5k80308, USA; email: dhope 18unledu.

Received: October 10, 2005

Accopted: April 6, 2006

Available online 18 September 2006 